\title{
EDITORIALE
}

\section{MAKING YOUR MARK IN ACADEMIA}

\author{
by Peter LaPlaca*
}

Most marketing professors want to get published. And the goal is increasingly not just to get published, but to get cited. Even with a growing plethora of marketing journals in the world (there are now over 240 marketing journals published in English around the world), it is increasingly more difficult to get research papers accepted in the twenty-to-thirty top journals. What gets you published, and what gets you cited?

\section{Getting published}

At an Elsevier editors' conference several years ago, a question was posed: What constitutes a world-class paper? A group of editors from a wide variety of disciplines reached, what I think is, as very clear analysis of what it takes to write an article that not only gets accepted, but becomes recognized as an excellent piece of research.

It all begins with the research topic. If you are researching a topic that no one is interested in (other than you, your spouse and maybe your parents), chances are that no journal will be interested in publishing it. So first of all find a research area that is generating considerable discussion in the academic community. How? Go to conferences and listen to what is being talked about. What are the leading researchers currently investigating? Read the latest issues of top journals. (And also look at the articles in press section of journal websites.) And, of course, look at calls for papers from the journals themselves; these tell you explicitly that the journal will be interested in reviewing papers consistent with the CFP. A topic that is

* Editor-in-Chief, Industrial Marketing Management 


\section{P. LaPlaca}

both new and exciting has a far greater chance of acceptance than a paper that is old or boring.

Secondly you must target the right journals. Every journal has a mission and will only publish papers consistent with that mission. Submit an excellently written paper to the wrong journal and it will be rejected.

What type of article do you want to write? Well written review articles generally received high levels of acceptance, but these can take a long time to write (up to two years or more) and have a longer review cycle due to their breadth. I recommend that these be undertaken only by well-established, senior faculty members. Research articles are the most common types of articles and focus on a specific, and generally narrow, aspect of a discipline. But be sure it satisfies the new and exciting criteria discussed above. Communications are short articles usually fewer than 2000 words and can be used to comment on previously published articles. Not all journals accept communications, so check before you submit.

Both content and presentation are important in getting a paper accepted for publication. Content means the paper must have a clear, useful and exciting message. Presentation means that the paper conveys the authors' thoughts in a logical manner such that the reader arrives at the same conclusions as the author; it is constructed in the format that best showcases the authors' material; and it is written in a style that transmits the message clearly and is consistent with the journal's writing style.

Always remember that you must write your paper for the reader and the first reader is the reviewer! The structure of your paper generally follows the following format: title, abstract, keywords, main text (introduction, methods, results and discussion) and references. Let's look at each of these aspects of the paper;

Title - Does the title immediately grab the reader's (reviewer's) attention? Is it clear to the reader what the article is focused on? Does the reader say "This should be interesting!" A good title should contain the fewest possible words that adequately describe the contents of a paper. Effective titles identify the main issue of the paper; begin with the subject of the paper; are accurate, complete, specific and unambiguous; and attract the reader.

Abstract - Is an advertisement for your paper. Not only must it compel the reviewer to read the paper, it must also compel a potential reader who may only have access to the abstract on a journal website to acquire the article. To do so the abstract must briefly describe the research and highlight your findings!

Keywords - While we all know that keywords are used in web searches, we should also be aware that keywords are used by editors to assign papers to reviewers and improper keywords can get papers assigned to the wrong reviewers. 
Main text - introduction - The job of the introduction is to convince the reader (reviewer) that your work is important and warrants publication. As such the introduction should contain: the topic, a statement of the problem you are solving and why it is relevant, how it fits into the extant knowledge and extends the limits of knowledge, specific research questions, what is its contribution, and an overview of the paper.

Main text - Methods - How did you study the problem? The basic principles: to provide sufficient information so that a knowledgeable reader can reproduce the research and/or determine that the methods used were appropriate and unbiased for the problem studied. For empirical papers this will include material studied, area descriptions, methods, techniques, theories applied. For case study papers this will include application of existing methods, theory or tools and special settings in this piece of work. For methodological papers this will include materials and detailed procedures undertaken. And for theory papers it will include principles, concepts, and models and major framework and derivations.

Main text - Results - What have you found? What are the main findings listed in association with the methods? Highlight differences between your results and the previous publications (especially in case study papers). Clearly show the results of statistical analysis and results of performance analysis (especially in the methodology, or algorithm papers). And, if appropriate, a set of principle equations or theorems supporting the assumptions after a long chain of inferences (especially in the theory papers)

Main text - Discussion - What do the results mean? How do your results relate to the original question or objectives outlined in the Introduction section? Can you reach your conclusions smoothly after your discussion? Do you provide interpretation for each of your results presented? Are your results consistent with what other investigators have reported? Or are there any differences? Why? Are there any limitations?

Main text - conclusions - How does your work advances the field from the present state of knowledge? You should present global and specific conclusions, in relation to the objectives; indicate uses, extensions, and limitations if appropriate; and suggest future research and point out those that are underway.

References - We all build our research based on previous work done by others. Your references must show that you have explored previous research. Therefore you should cite the most important relevant articles, not everything previously published on the subject. 


\section{P. LaPlaca}

\section{Getting cited}

To help answer the second question, I decided to look at the most cited articles that had been published in Industrial Marketing Management. To prepare for this I first looked at the most downloaded articles from IMM and then I used Google Scholar to determine the citation counts for these articles. A representative sampling of these articles is:

1. From goods to service(s): Divergences and convergences of logics, Volume 37, Issue 3, May 2008, Pages 254-259, SL Vargo, RF Lusch

2. Organizing for solutions: Systems seller vs. systems integrator, Volume 36, Issue 2, February 2007, Pages 183-193, A Davies, T Brady, M Hobday

3. Demand chain management-integrating marketing and supply chain management, Volume 36, Issue 3, April 2007, Pages 377-392, U Jüttner, M Christopher, S Baker

4. Measuring inter-organizational trust-a critical review of the empirical research in 1990-2003, Volume 36, Issue 2, February 2007, Pages 249-265, R Seppänen, K Blomqvist, S Sundqvist

5. It's all B2B...and beyond: Toward a systems perspective of the market, Volume 40, Issue 2, February 2011, Pages 181-187, SL Vargo, RF Lusch

6. An evaluation of divergent perspectives on customer relationship management: Towards a common understanding of an emerging phenomenon, Volume 33, Issue 6, August 2004, Pages 475-489, AR Zablah, DN Bellenger, WJ Johnston

7. Supplier relationships: emerging issues and challenges, Volume 26, Issue 1, January 1997, Pages 91-100, JN Sheth, A Sharma

8. Marketing solutions in accordance with the S-D logic: Co-creating value with customer network actors, Volume 37, Issue 3, May 2008, Pages 270-277, B Cova,R Salle

9. Rise of strategic nets - New modes of value creation, Volume 36, Issue 7, October 2007, Pages 895-908, K Möller, A Rajala

10. Leadership and organizational learning's role on innovation and performance: Lessons from Spain, Volume 36, Issue 3, April 2007, Pages 349-359, JA Aragón-Correa, VJ García-Morales, E CordónPozo.

These ten articles all received between 125 and 400 citations. Is that a large number? Considering that one of the most cited marketing articles "Evolving to a New Dominant Logic in Marketing" (Stephen Vargo and Robert Lusch, Journal of Marketing, 68/1, January 2004) has received almost 4000 citations in fewer than a dozen years, it may seem that these are not too many. But considering that the vast majority of published marke- 
ting articles receive fewer than ten citations, this small sample from IMM seems to have received a rather healthy number of citations.

\section{What makes these articles so widely cited?}

Articles that are widely cited fall into three categories: those that provide a new tool or methodology for other researchers to use; those that resolve conflicts in previously published research; those that introduce new perspectives or paradigms. Let's look at each of these categories.

New tools or methodologies - These articles provide researchers with new ways of obtaining information from markets or new ways of analyzing market data for better insight. These might include new survey instruments, new scales, innovative experimental designs or procedures or other ways to help other researchers in their own work. Occasionally new ways of analyzing data are also introduced or applications of data analysis from different fields are used in market research. In each case an author using the new tool or methodology will generally cite the article as justification for their use of it.

Resolve conflicts in previously published research - It is not unusual to see conflicting conclusions in different articles dealing with the same phenomena. And both articles might be correct! An astute researcher who can successfully explain these seemingly contradictory results brings new insights to the field and can frequently be cited by both sides of the controversy.

Introduce new perspectives of paradigms - As shown by the oft cited Vargo and Lusch article that introduced the service-dominant paradigm, these kinds of articles are almost always cited by anyone publishing an article associated with the new perspective. Ted Levitt's "Marketing Myopia" in the Harvard Business Review (Jan 1960) is another example of a paradigm setting article that received thousands of citations. Because these articles have established a foundation for future research, anyone writing in these new areas almost is compelled to cite the groundbreaking work.

I hope that these brief comments prove useful to you as you plan your research agenda and prepare research papers for submission to journals. If you do get a letter rejecting your submission don't despair. At top journals over 80 percent of submissions are rejected. Read the reviewer comments. Where possible, make improvements as suggested by the reviewers and submit the paper to another journal. Remember that it is the paper that was rejected and not the author. 